\title{
Physicochemical factors affecting the wettability of copper mine blasting dust
}

\author{
Longzhe Jin ${ }^{1,2,3} \cdot$ Jianguo Liu ${ }^{1,2,3}$ (I) Jingzhong Guo ${ }^{1,4} \cdot J^{\prime a y i n g ~ W a n g}{ }^{1} \cdot$ \\ Tianyang Wang ${ }^{1}$
}

Received: 26 December 2019/Revised: 23 December 2020/ Accepted: 21 January 2021 / Published online: 12 February 2021

(C) The Author(s) 2021

\begin{abstract}
To investigate the factors affecting the wettability of copper mine blasting dust, the primary blasting dust was collected from an open-pit copper mine and separated into hydrophilic blasting dust (HLBD) and hydrophobic blasting dust (HBBD) using water flotation method. The physicochemical properties of HLBD and HBBD were measured and compared with each other. The properties included particle size distributions (PSDs), micromorphologies, pore structures, mineral components and surface organic carbon functional groups. The results show that particle size and pore structure of the blasting dust are the main factors affecting its wettability. Specifically, particle size of HBBD is smaller than that of HLBD, and their respiratory dust (less than $10 \mu \mathrm{m}$ ) accounts for $61.74 \mathrm{vol} \%$ and $53.00 \mathrm{vol} \%$, respectively. The pore structure of HBBD is more developed, and the total pore volume of HBBD is 1.66 times larger than that of HLBD. The identical mineral compositions were detected in HLBD and HBBD by X-rays diffraction (XRD); however, the surface organic hydrophobic component of HBBD is slightly larger than that of HLBD, this may be the reason for the poor wettability of HBBD. This study is significant to understand the effects of physicochemical properties of copper mine blasting dust on its wettability.
\end{abstract}

Keywords Blasting dust $\cdot$ Copper mine $\cdot$ Wettability $\cdot$ Physicochemical properties

\section{Introduction}

Blasting remains one of the most widely used methods in open-pit mines worldwide (Singh et al. 2015; Pérez et al. 2018), although it produces massive emissions of fine particles and toxic gases (Akbari et al. 2015; Abdollahisharif et al. 2016; Liu et al. 2019a; Taylor et al. 2014). Those fine particulates not only can increase the prevalence of pneumoconiosis in mineworkers (Petavratzi et al. 2005; $\mathrm{Xu}$ et al. 2018), but also pollute atmospheric environment (Csavina et al. 2012).

Many studies have been performed to control mine blasting dust in recent years. Yu et al. (2018), Huang et al. (2019a, b) studied the diffusion process of blasting dust from mines using numerical simulation. Abdollahisharif et al. (2016) proposed a green biocompatible approach (i.e., ionized water stemming) to reduce the toxic gases and dust caused by the blasting in surface mining. Jin et al. (2007) experimented with the same approach in an underground 
driving rock tunnel. In addition, water filled ampoules and water filled balls were used to reduce the blasting dust in India (Bhandari et al. 2004). As described above, although many new techniques are proposed to suppress mine dust, water spray and chemical dust suppressant are still the most widely utilized methods for dust control in the field (Konorev and Nesterenko 2012; Du and Li 2013; Huang et al. 2019a, b; Gonzalez et al. 2019).

For water spray and chemical dust suppressant, dust wettability is a vital parameter and can largely determine the suppressant efficiency (Xu et al. 2018; Liu et al. $2019 b)$. Therefore, considerable studies were conducted on the wettability of mine dust recent years. Study performed by Wang et al. (2019a, b) shows particle diameter is one of the most significant factors affecting the wettability of coal dust among many physical and chemical factors. Xu et al. (2017) investigated the effects of chemical properties of coal dust on its wettability, showing the proximate components and surface carbon functional groups of coal dust are highly correlated with its wettability, and increased moisture content and large carbonyl group content can improve coal dust wettability. In addition, Li et al. (2013) studied the effects of surface physical properties of respirable coal dust on its wettability, and their results demonstrate the pore structure of coal dust, besides of particle size, has a significant effect on its wettability, and larger pore volume and larger surface area lead to poor wettability. As mentioned above, lots of studies were performed on the wettability of coal dust, however, there are few studies performed on the wettability of ore dust, such as blasting dust in metal mines. Our previous studies (Liu et al. 2019a) investigated the wettability of iron mine blasting dust, but to our knowledge, there is still no study on the wettability of copper mine blasting dust.

The objective of this study is to investigate the effects of physicochemical properties of copper mine blasting dust on its wettability. First, the primary blasting dust was collected from the Dexing open-pit copper mine located in Jiangxi province, China; then, the hydrophilic blasting dust (HLBD) and hydrophobic blasting dust (HBBD) were separated using water flotation method; after that, the physicochemical properties of HLBD and HBBD were comprehensively characterized. These properties included wettability, particle size distribution (PSD), micromorphology, pore structure, mineralogy, and surface organic carbon functional groups. Finally, these properties of HLBD and HBBD were compared with each other to identify the main factors affecting the wettability. This study is significant to understand the physicochemical properties of copper mine blasting dust and their effects on the wettability.

\section{Materials and experiments}

\subsection{Collection and pretreatment of the blasting dust sample}

As shown in Fig. 1, the primary blasting dust was collected from the Dexing open-pit copper mine in Jiangxi Province, China.

Frist, the mixture of deposited dust and small stones (Fig. 2a) was collected together in a plastic bag at the blasting site and immediately transported to the laboratory. Then, the blasting dust (Fig. 2b) was separated from the mixture using a 200 mesh $(74 \mu \mathrm{m})$ sieve. After that, the blasting dust was slowly poured into deionized water (prepared by a reverse osmosis instrument and with a surface tension of $73.02 \mathrm{mN} / \mathrm{m}$ ), as shown in Fig. $2 \mathrm{c}$ and d, the blasting dust was divided into two parts. The particles floated on the surface of deionized water were unwetted dust, called hydrophobic blasting dust (HBBD); in contrast, the particles deposited at the bottom of deionized water were wetted dust, called hydrophilic blasting dust (HLBD). Finally, HBBD and HLBD were extracted with a slide glass and dried at $100{ }^{\circ} \mathrm{C}$ for $2 \mathrm{~h}$. The same experimental method was carried out in our previous study (Liu et al. 2019b).

\subsection{Wettability test}

Contact angle (CA), the angle between base line and tangent line of water drop and as indicated in Fig. 3a, is a parameter that can directly reflect the wettability of dust (Chen et al. 2019). In this study, the dynamic CAs between the blasting dust and deionized water were measured on a
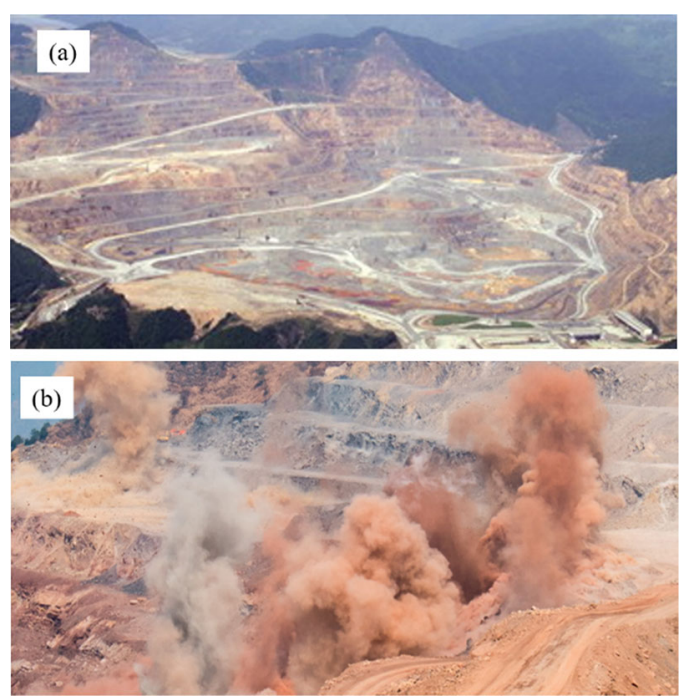

Fig. 1 Top view of Dexing open-pit copper mine a and its blasting scene $\mathbf{b}$ 

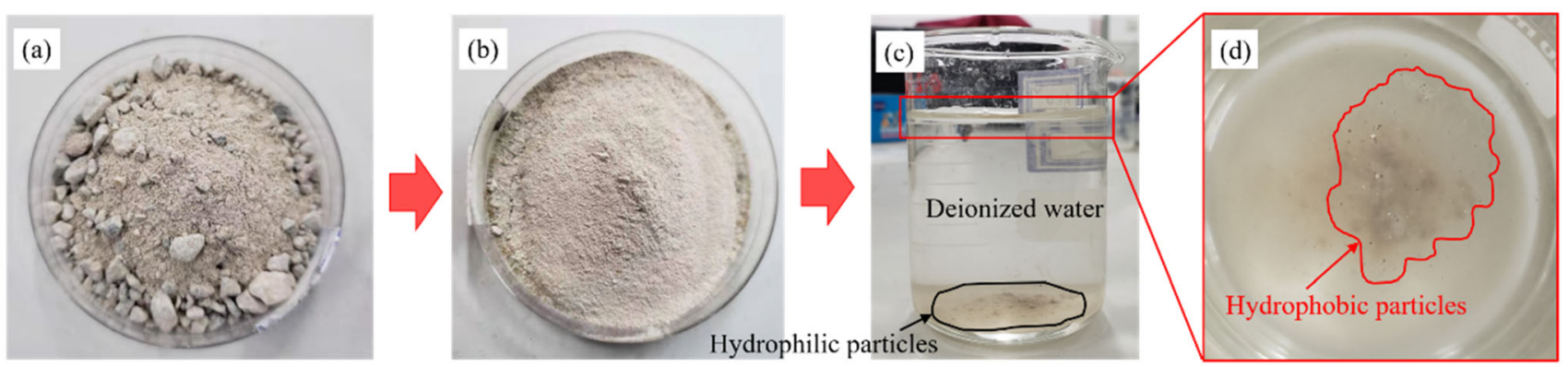

Fig. 2 The mixture of blasting dust and small stones a blasting dust $\mathbf{b}$ hydrophilic blasting dust $\mathbf{c}$ and hydrophobic blasting dust $\mathbf{d}$ in deionized water

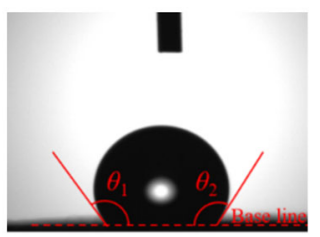

(a)

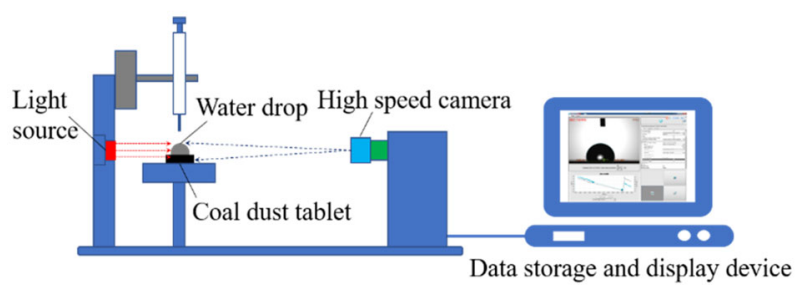

(b)

Fig. 3 Schematic diagram of contact angle a and Theta Lite TL101 apparatus b

Theta Lite TL101 apparatus at $7.5 \mathrm{~Hz}$ for $6 \mathrm{~s}$. As shown in Fig. 3a, the average value of $\theta_{1}$ (left CA) and $\theta_{2}$ (right CA) were recorded by a OneAttension software. The schematic diagram of the CA testing apparatus is shown in Fig. $3 \mathrm{~b}$.

\subsection{Physical properties test}

\subsubsection{Particle size distribution (PSD) and micromorphology test}

The deposition property of dust in human respiratory system is almost dependent on the PSD of the particulates (Oberdörster et al. 2005). In this study, the PSDs of HLBD and HBBD were measured in a laser particle size analyzer (LPSA) (Winner 2000) with a $20 \mathrm{vol} \%$ alcoholic solution used as dispersion liquid. In addition, to verify the PSD results and investigate the micromorphology of the blasting dust, scanning electron microscope (SEM) tests of HLBD and HBBD were performed on a SU8000 apparatus. The test results were analyzed using an ImageJ software.

\subsubsection{Pore structure test}

The pore structure of a particle can affect its wettability by adsorbing air to form an air film (Yang et al. 2010). Lowpressure $\mathrm{N}_{2}$ gas adsorption (LP- $\mathrm{N}_{2} \mathrm{GA}$ ) experiments were conducted for HLBD and HBBD on a 3H-2000PS2 apparatus for relative pressures $\left(P / P_{0}\right.$, gas pressure/saturated vapor pressure) ranging from 0.010 to 0.995 . As shown in Table 1, multiple adsorption theories were used to calculate the pore parameters of the blasting dust (Clarkson and Bustin 1999; Nie et al. 2015). The measurement was carried out only once considering the high accuracy of the apparatus.

\subsection{Chemical properties test}

The mineral compositions and carbon functional groups of HLBD and HBBD were characterized by X-ray diffraction (XRD) and X-ray photoelectron spectroscopy (XPS) tests, respectively. The XRD patterns were obtained from diffraction angles of $5^{\circ}-100^{\circ}$ with an angular speed of $2^{\circ} \%$ min on an Ultima IV (Rigaku) at $40 \mathrm{kV}$ and $40 \mathrm{~mA}$ with a $\mathrm{Ni}$-filtered $\mathrm{Cu} \mathrm{K} \alpha$ radiation source. The data were then

Table 1 Utilized multiple adsorption theories and corresponding pore parameters

\begin{tabular}{|c|c|c|}
\hline No. & $\begin{array}{l}\text { Multiple adsorption } \\
\text { theory }\end{array}$ & Pore parameter \\
\hline 1 & $\begin{array}{l}\text { Brunauer-Emmett- } \\
\text { Teller (BET) }\end{array}$ & Specific surface area (SSA) \\
\hline 2 & Langmuir & SSA \\
\hline 3 & $\begin{array}{l}\text { Barrett-Joyner- } \\
\text { Halenda (BJH) }\end{array}$ & Mesopore volume and mesopore size \\
\hline 4 & $\begin{array}{l}\text { Dubinin- } \\
\text { Radushkevich (D- } \\
\text { R) }\end{array}$ & Micropore volume \\
\hline 5 & $\begin{array}{l}\text { Density functional } \\
\text { theory (DFT) }\end{array}$ & $\begin{array}{l}\text { Pore size distributions and } \\
\text { cumulative pore volumes }\end{array}$ \\
\hline
\end{tabular}


analyzed using MDI Jade 6.1 software. The XPS tests were carried out on an AXIS ULTRA spectrometer (Kratos) with an $\mathrm{Al} \mathrm{K} \alpha$ radiation source and a detection area of $700 \mu \mathrm{m}$ $\times 300 \mu \mathrm{m}$. The binding energies were calibrated using the $\mathrm{C}$ 1s peak with a reference of $248.8 \mathrm{eV}$. Four carbon functional groups were fitted using XPSPEAK 4.1 software, and their relative contents $(n)$ were calculated with Eq. (1):

$n_{j}=\frac{S_{j}}{\sum_{i=1}^{N} S_{i}}$

where, $n_{j}$ is the relative content of the functional group $j, S_{j}$ is the peak area of the functional group $j$, and $N$ is the number of fitting peaks.

\section{Results and discussion}

\subsection{Wettability analysis}

Figure 4 illustrates the shapes of water droplets formed on the surface of the blasting dust platelets at different times. The shapes of the water drop on the both HBBD and HLBD surfaces flatten continuously with time because of thermodynamic and kinetic adsorption into the blasting dust platelets (Susana et al. 2012). Figure 4 clearly shows that the wettability of HLBD is higher than that of HBBD as the water drop shapes on HLBD are consistently thinner than on HBBD. This result verified the effectiveness of water floatation method (Fig. 2) for separating hydrophilic and hydrophobic particles from copper mine blasting dust.

Figure 5 shows the curves of CAs of HBBD and HLBD over time. The CAs of HBBD and HLBD at $0 \mathrm{~s}$ (initial contact angle) are $74^{\circ}$ and $31^{\circ}$, respectively; after that, they decrease sharply over time in a parallel manner. After $1.07 \mathrm{~s}$, the CA of HLBD is too small to identified, while the HBBD contact angle is $38^{\circ}$ with a slow decreasing rate. This result indicates that the wettability of HBBD is essentially different from that of HLBD and provides the

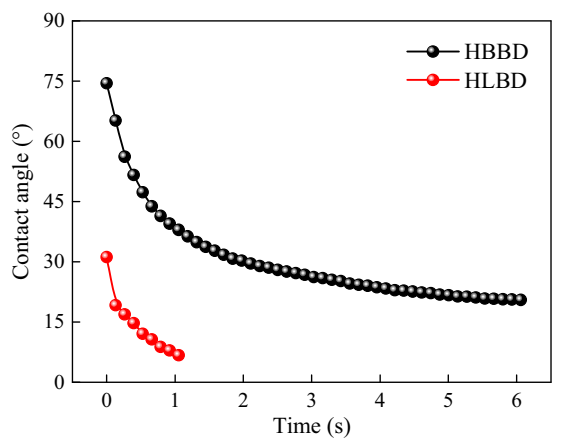

Fig. 5 Contact angles of HBBD and HLBD over time

basis for studying the factors affecting the wettability of copper mine blasting dust by comparing its physical and chemical properties.

\subsection{Particle size distribution (PSD) analysis}

The particle size of the blasting dust was measured using a laser particle size analyzer (LPSA). Figure 6 shows the differential and accumulative PSDs of HBBD and HLBD, and Table 2 summarizes the particle size value of $D_{10}, D_{50}$, $D_{90}$ (where $10 \mathrm{vol} \%, 50 \mathrm{vol} \%$, and $90 \mathrm{vol} \%$ of dust is less than the particle size values, respectively), and $P_{10}$ (the percentage of dust with particles less than $10 \mu \mathrm{m}$ in size). Figure $6 \mathrm{c}$ illustrates the meaning of the symbols in Table 1.

Figure 6 and Table 2 indicate that the size distributions of HBBD and HLBD present a single peak structure, and the $D_{50}$ value of $\operatorname{HBBD}(7.71 \mu \mathrm{m})$ is less than that $\operatorname{HLBD}(9.94 \mu \mathrm{m})$. The $D_{50}$ values of HBBD and HLBD are all smaller than that of coal dust reported by Kollipara et al. (2014). This result suggests that the blasting dust is more likely to be inhaled than coal dust due to its finer size. In addition, the volume percentage of respirable dust (smaller than $10 \mu \mathrm{m}$, i.e., $P_{10}$ ) in HBBD is higher $8.74 \mathrm{vol} \%$ than that in HLBD. Therefore, HBBD is more difficult to suppress than HLBD because of its stronger hydrophobicity

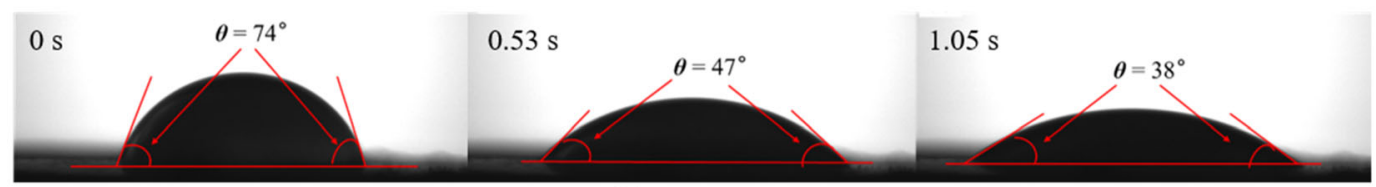

(a) HBBD

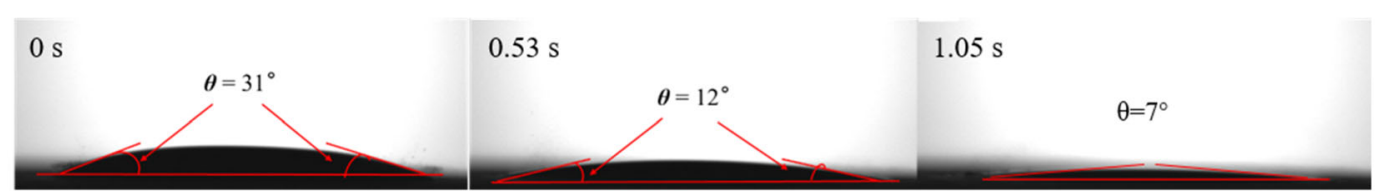

(b) HLBD

Fig. 4 Images of water droplets on a compressed HBBD platelet a and HLBD platelet $\mathbf{b}$ at various times 

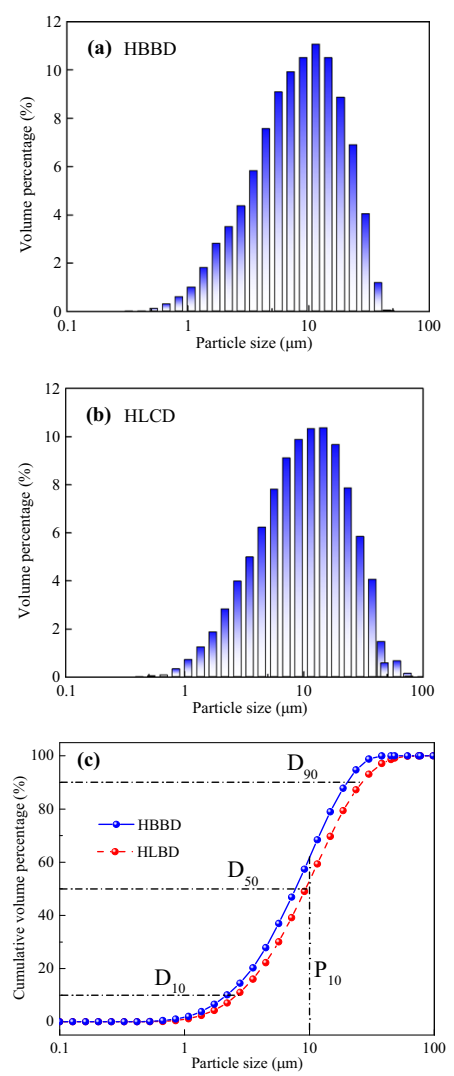

Fig. 6 Differential PSD of HBBD a and HLBD $\mathbf{b}$ and their accumulative PSD c

Table 2 Particle size distribution of HBBD and HLBD

\begin{tabular}{lllll}
\hline Dust sample & $D_{10}(\mu \mathrm{m})$ & $D_{50}(\mu \mathrm{m})$ & $D_{90}(\mu \mathrm{m})$ & $P_{10}(\mathrm{vol} \%)$ \\
\hline HBBD & 2.16 & 7.71 & 20.06 & 61.74 \\
HLBD & 2.62 & 9.94 & 26.37 & 53.00 \\
\hline
\end{tabular}

and smaller particle size. Consequently, HBBD is more harmful to humans in open-pit copper mines.

According to the studies conducted by Yang et al. (2010) and Li et al. (2013), smaller dust particles have a more unsaturated surface, which causes the adsorption of air and formation of an air film on the dust surface. The air film prevents water drops from direct contacting the particles; thus, the air film lowers the wettability of the dust. For this reason, more considerations are needed on suppression technology for small hydrophobic blasting dust in copper mines.

\subsection{Micromorphology analysis}

Figure 7 shows the SEM pictures of HBBD and HLBD. It can be seen that HBBD particle size is smaller than that of
HLBD, which is consistent with the LPSA result. In addition, the micromorphology of the blasting dust consists mainly of irregular flakes and needles, which is completely different from the irregular spherical or bulky morphology of coal dust (Li et al. 2013; Kollipara et al. 2014; Hong et al. 2017). This phenomenon is caused mostly by the difference in production mechanisms between the blasting dust and coal dust. Coal dust is caused by friction between a cutting machine and the coal body, whereas the blasting dust is produced from rock under strong explosive wave action (Liu et al. 2019b). Furthermore, hardness of rock from that of coal may also contribute to distinct dust micromorphology. A comparison of Fig. 7a and b shows that HBBD contains a number of needle shape particles, and they adhere together and form rough surface; however, HLBD contains most of flake or block shape particles, and their surface is smoother than HBBD surface. That is, HBBD surface roughness is larger than that of HLBD. This is consistent with the results reported by Yang et al. (2010), Li et al. (2013) and Wang et al. (2019a, b), i.e., smaller dust particles have rougher surfaces. Surface roughness can enhance both hydrophilicity and hydrophobicity, which depends on the wettability of the substance (Tian and Jiang 2013). Specifically, hydrophilic surface can be enhanced more hydrophilic by increasing its surface roughness, but hydrophobic surface will get more hydrophobic when its surface become more roughness.

\subsection{Pore structure properties analysis}

Figure 8 illustrates the adsorption-desorption isotherms of HBBD and HLBD. The adsorption volume of HBBD at the highest pressure is $14.2 \mathrm{~cm}^{3} / \mathrm{g}$, which is higher than that of $\operatorname{HLBD}\left(8.2 \mathrm{~cm}^{3} / \mathrm{g}\right)$, indicating that the porosity of HBBD is more developed than that of HLBD. Table 3 shows the quantitative comparison of HBBD and HLBD pore parameters, including specific surface area (SSA), pore volume, and pore size, which were calculated based on the theories of BET and Langmuir, BJH and D-R, and BJH, respectively.

The result shows that the Langmuir SSA and the BJH pore sizes are all larger for HBBD than for HLBD. The mesopore volume (BJH volume) and total volume of HBBD are also much greater than that of HLBD, demonstrating that HBBD pore structure is more complex than that of HLBD.

Moreover, as shown in Fig. 9, pore size distributions and cumulative pore volumes of the blasting dust were obtained based on DFT theory. The results indicate that under the action of an explosive wave, the HBBD and HLBD micropores are more developed than the coal dust reported by Yang et al. (2010), and their maximum pore volume is reached at pore sizes of $1.14 \mathrm{~nm}$ and $0.84 \mathrm{~nm}$, 

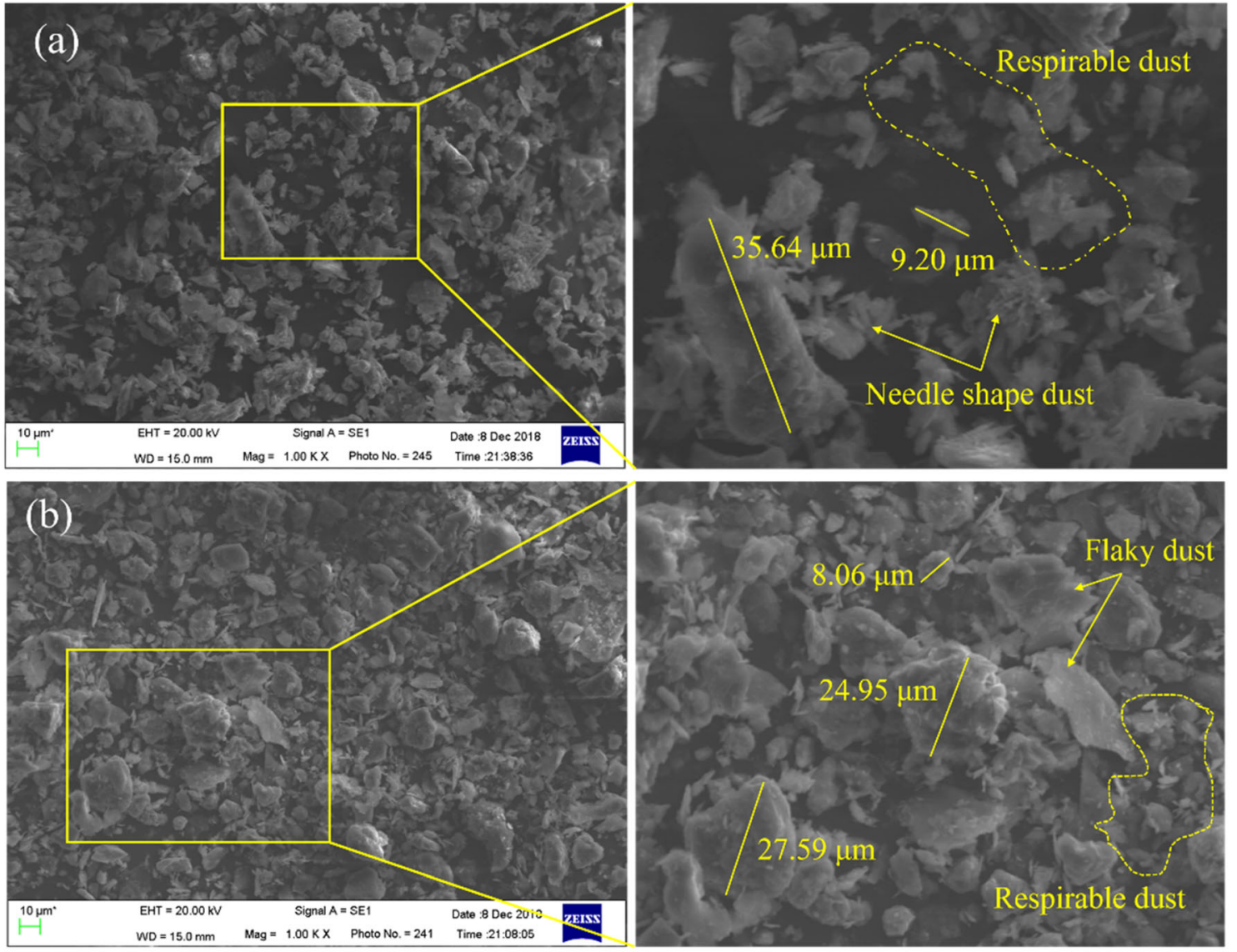

Fig. 7 SEM images of HBBD a and HLBD b

respectively. After that point, pore volume decreases with increasing pore size. HLBD micropore volume is also larger than that of HBBD for pore sizes less than $1.09 \mathrm{~nm}$ (Fig. 9a). As a result, the D-R volume of HLBD is larger than that of HBBD (Table 3). However, when the pore size is larger than $1.09 \mathrm{~nm}, \mathrm{HBBD}$ pore volume is always larger than that of HLBD, and the maximum cumulative pore volume of HBBD is 1.68 times that of HLBD.

\subsection{XRD and XPS analyses}

The mineral component is a key chemical factor affecting the wettability of dust because it determines the surface energy (Tian and Jiang 2013). The three identical mineral compositions in HBBD and HLBD were observed from XRD patterns, i.e., quartz, calcite, and muscovite, as shown in Fig. 10. This result indicates that mineral composition is not the reason for the different wettability of HBBD and HLBD.

The surface organic component is another chemical factor affecting wettability of dust (Xu et al. 2017). In this section, XPS tests were performed for HBBD and HLBD. As shown in Fig. 11, the $\mathrm{C}$ 1s spectrogram was divided into four peaks using the peak-split method, and relative peak areas (RPEs) were calculated following Eq. (1). Table 4 presents the results.

Generally, oxygen-containing functional groups are hydrophilic, and aliphatic hydrocarbons $(\mathrm{C}-\mathrm{C} / \mathrm{C}-\mathrm{H})$ are hydrophobic (Zhou et al. 2015; Wang et al. 2017; Xu et al. 2017). Table 4 shows that the hydrophobic groups on the surface of the blasting dust are more numerous in organic carbon groups. The relative peak area (RPA) of hydrophobic groups in HBBD is slightly higher than that in HLBD, whereas all hydrophilic HLBD groups have a higher RPA. This phenomenon indicates that the hydrophobic carbon functional groups may affect the wettability of the blasting dust, but more experiments are needed to support this conclusion.

\section{Conclusion}

To investigate the factors affecting the wettability of copper mine blasting dust, the hydrophilic blasting dust (HLBD) and hydrophobic blasting dust (HBBD) were separated from the blasting dust at the Dexing copper mine; 

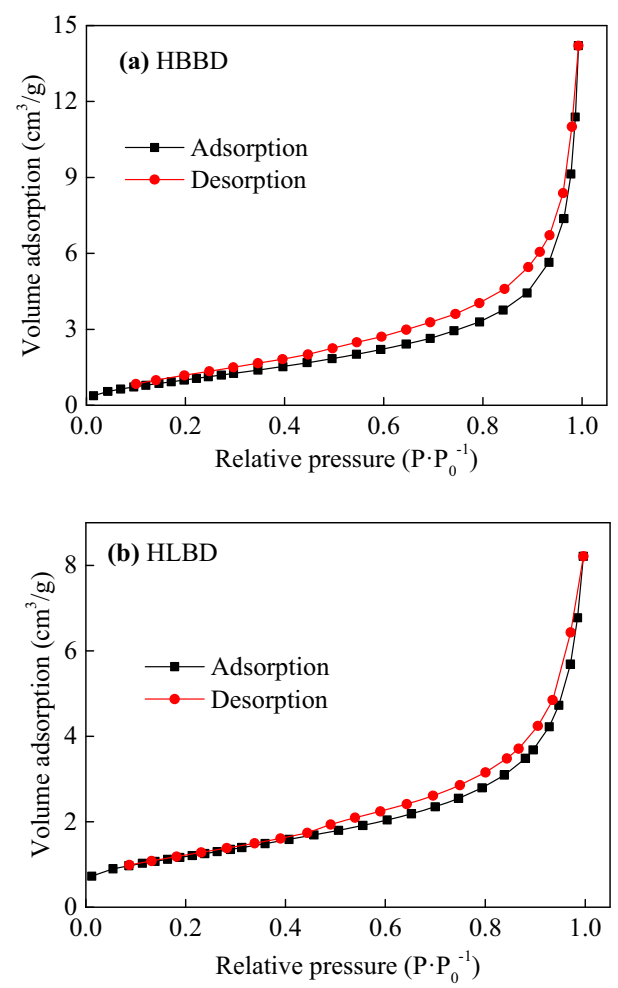

Fig. 8 Adsorption-desorption isotherms of HBBD a and HLBD $\mathbf{b}$

Table 3 Pore structure parameters of HBBD and HLBD

\begin{tabular}{|c|c|c|c|c|c|c|}
\hline \multirow{2}{*}{$\begin{array}{l}\text { Dust } \\
\text { Sample }\end{array}$} & \multicolumn{2}{|c|}{$\operatorname{SSA}\left(\mathrm{m}^{2} / \mathrm{g}\right)$} & \multicolumn{3}{|c|}{ Pore volume $\left(\mathrm{cm}^{3} / \mathrm{g}\right)$} & \multirow{2}{*}{$\begin{array}{l}\mathrm{BJH}^{\mathrm{d}} \\
\text { pore } \\
\text { size }(\mathrm{nm})\end{array}$} \\
\hline & $\begin{array}{l}\text { BET } \\
\text { SSA }\end{array}$ & $\begin{array}{l}\text { Langmuir } \\
\text { SSA }\end{array}$ & $\begin{array}{l}\mathrm{BJH}^{\mathrm{a}} \\
\text { volume }\end{array}$ & $\begin{array}{l}\mathrm{D}-\mathrm{R}^{\mathrm{b}} \\
\text { volume }\end{array}$ & $\begin{array}{l}\text { Total } \\
\text { volume } \\
\text { c }\end{array}$ & \\
\hline HBBD & 4.24 & 7.26 & 0.0241 & 0.0015 & 0.0256 & 12.625 \\
\hline HLBD & 4.29 & 6.99 & 0.0133 & 0.0021 & 0.0154 & 10.505 \\
\hline
\end{tabular}

${ }^{\mathrm{a}}$ Mesopore volume

${ }^{\mathrm{b}}$ Microvolume

${ }^{\mathrm{c}}$ Total volume $=$ mesopore volume + microvolume

${ }^{\mathrm{d}}$ Mesopore size

and then, their physicochemical properties were comprehensively measured. The following conclusions were drawn from this study:

(1) The particle size of the blasting dust is small; $P_{10}$ (the percentage of dust with particles less than $10 \mu \mathrm{m}$ in size) of HBBD and HLBD is $61.74 \%$ and $53.00 \%$ by volume, respectively. HBBD is difficult to suppress due to its stronger hydrophobicity and a larger number of respiratory particles.

(2) HBBD has a more developed pore structure than HLBD based on the LP- $\mathrm{N}_{2}$ GA test and SEM images. The total pore volume of HBBD is 1.66 times that of
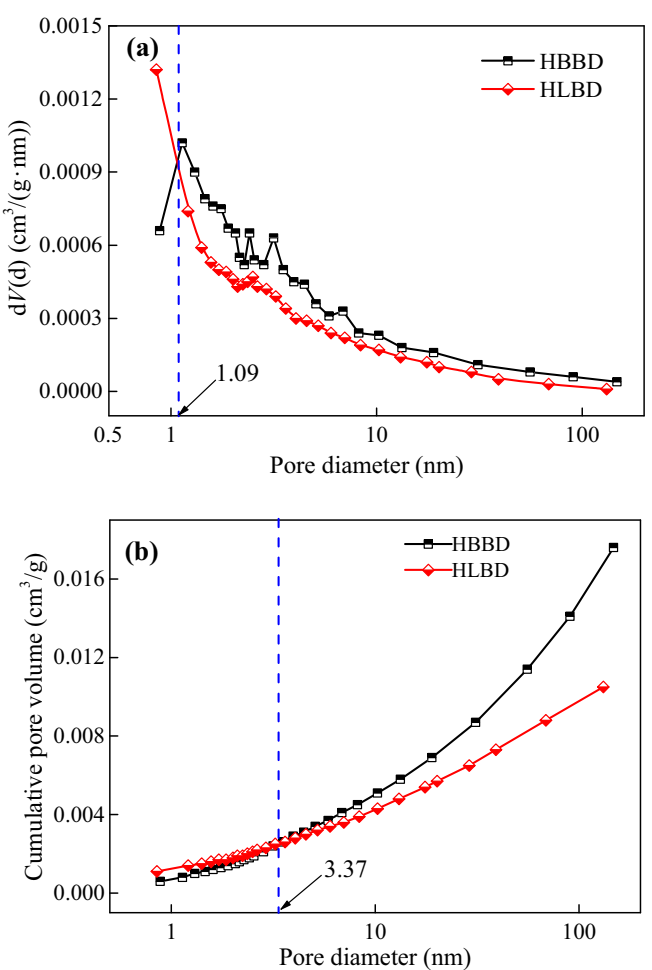

Fig. 9 Pore size distributions $\mathbf{a}$ and cumulative pore volumes $\mathbf{b}$ of HBBD and HLBD

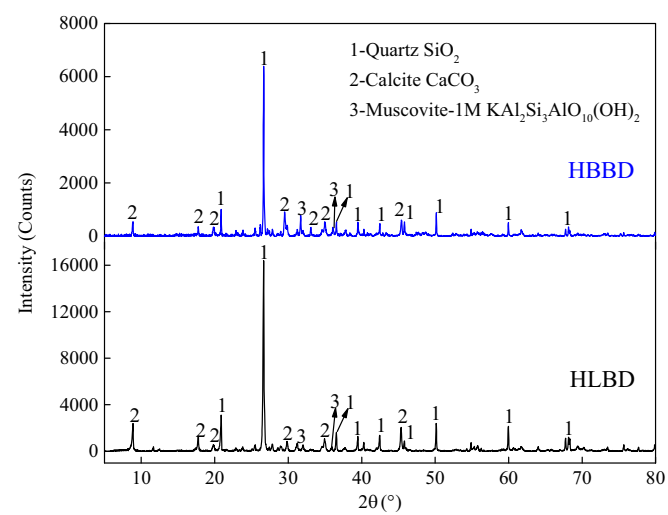

Fig. 10 XRD patterns of HBBD and HLBD

HLBD. The developed pore structure promotes the formation of an air film on the dust surface that lowers its wettability.

(3) Particle size and pore structure are two key factors affecting the wetting properties of the blasting dust. Smaller blasting dust have more complex pore structure and lower wettability.

(4) The mineral composition of the blasting dust is not a factor affecting its wettability as the same mineral compositions were found in HBBD and HLBD. However, the surface organic hydrophobic component in HBBD is slightly larger than that in HLBD, 

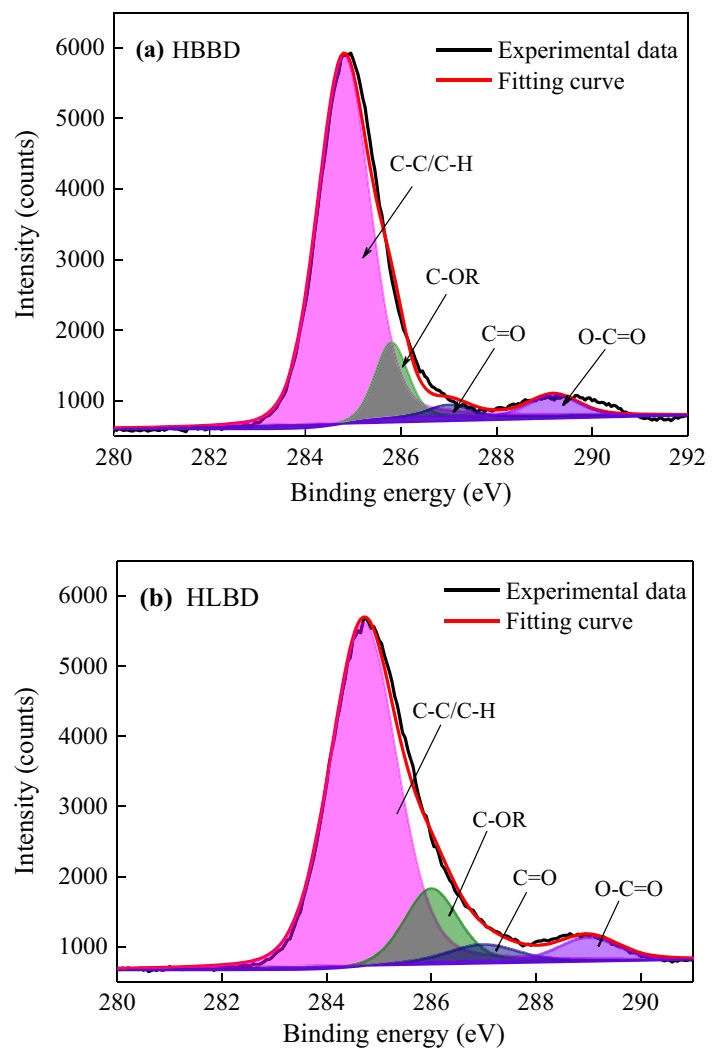

Fig. $11 \mathrm{C}$ 1s XPS patterns of HBBD a and HLBD b

Table 4 Relative peak areas (RPA) of carbon functional groups

\begin{tabular}{|c|c|c|c|c|c|c|c|c|}
\hline \multirow{2}{*}{$\begin{array}{l}\text { Dust } \\
\text { sample }\end{array}$} & \multicolumn{2}{|c|}{$\mathrm{C}-\mathrm{C} / \mathrm{C}-\mathrm{H}$} & \multicolumn{2}{|l|}{$\mathrm{C}-\mathrm{O}$} & \multicolumn{2}{|l|}{$\mathrm{C}=\mathrm{O}$} & \multicolumn{2}{|c|}{$\mathrm{O}-\mathrm{C}=\mathrm{O}$} \\
\hline & $\begin{array}{l}\mathrm{BE} \\
(\mathrm{eV})\end{array}$ & $\begin{array}{l}\text { RPA } \\
(\%)\end{array}$ & $\begin{array}{l}\mathrm{BE} \\
(\mathrm{eV})\end{array}$ & $\begin{array}{l}\text { RPA } \\
(\%)\end{array}$ & $\begin{array}{l}\mathrm{BE} \\
(\mathrm{eV})\end{array}$ & $\begin{array}{l}\text { RPA } \\
(\%)\end{array}$ & $\begin{array}{l}\mathrm{BE} \\
(\mathrm{eV})\end{array}$ & $\begin{array}{l}\text { RPA } \\
(\%)\end{array}$ \\
\hline HBBD & 284.8 & 83.11 & 285.8 & 10.51 & 287.0 & 2.04 & 289.2 & 4.33 \\
\hline HLBD & 284.7 & 78.17 & 286.0 & 13.33 & 287.0 & 3.81 & 289.0 & 4.69 \\
\hline
\end{tabular}

Notes: $B E$ binding energy, $R P A$ relative peak area

which may be another factor causing the wetting ability of HBBD to be lower than that of HLBD.

Acknowledgements The authors are grateful to the National Nature Science Foundation of China (No. 51874015) and the National Key Research and Development Program of China (No. 2017YFC0805204).

Authors' contributions Jianguo Liu conceived and designed the investigation, collected data, performed the analysis, and wrote the paper. Longzhe Jin was the academic supervisor who conceived the study and provided financial support. Jingzhong Guo, Jiaying Wang and Tianyang Wang helped for the experiments.

Availability of data and materials Not applicable.
Code availability Not applicable.

\section{Compliance with ethical standards}

Conflict of interest The authors declare no conflicts of interest.

Open Access This article is licensed under a Creative Commons Attribution 4.0 International License, which permits use, sharing, adaptation, distribution and reproduction in any medium or format, as long as you give appropriate credit to the original author(s) and the source, provide a link to the Creative Commons licence, and indicate if changes were made. The images or other third party material in this article are included in the article's Creative Commons licence, unless indicated otherwise in a credit line to the material. If material is not included in the article's Creative Commons licence and your intended use is not permitted by statutory regulation or exceeds the permitted use, you will need to obtain permission directly from the copyright holder. To view a copy of this licence, visit http://creativecommons. org/licenses/by/4.0/.

\section{References}

Abdollahisharif J, Bakhtavar E, Nourizadeh H (2016) Green biocompatible approach to reduce the toxic gases and dust caused by the blasting in surface mining. Environ Earth Sci 75(3): 191

Akbari M, Lashkaripour G, Bafghi AY, Ghafoori M (2015) Blastability evaluation for rock mass fragmentation in Iran central iron ore mines. Int J Min Sci Technol 25(1):59-66

Bhandari S, Bhandari A, Arya S (2004) Dust resulting from blasting in surface mines and its control. In: Proceedings of explosive conference, pp 25-34

Chen YP, Xu G, Huang JX, Eksteen J, Liu XF, Zhao ZD (2019) Characterization of coal particles wettability in surfactant solution by using four laboratory static tests. Colloids Surf A 567:304-312

Clarkson CR, Bustin RM (1999) The effect of pore structure and gas pressure upon the transport properties of coal: a laboratory and modeling study. 1. Isotherms and pore volume distributions. Fuel 78(11):1333-1344

Csavina J, Field J, Taylor MP, Gao S, Landazuri A, Betterton EA, Sáez AE (2012) A review on the importance of metals and metalloids in atmospheric dust and aerosol from mining operations. Sci Total Environ 433:58-73

Du CF, Li L (2013) Development and characterization of formulation of dust-suppressant used for stope road in open-pit mines. J Coal Sci Eng 19(2):219-225

Gonzalez A, Aitken D, Heitzer C, Lopez C, Gonzalez M (2019) Reducing mine water use in arid areas through the use of a byproduct road dust suppressant. J Clean Prod 230:46-54

Hong S, Liu ZT, Zhao EL, Lin S, Qiu LM, Qian JF, Liu HX, Xia SK (2017) Comparison of behavior and microscopic characteristics of first and secondary explosions of coal dust. J Loss Prev Process Ind 49:382-394

Huang Z, Ge S, Jing D, Yang L (2019) Numerical simulation of blasting dust pollution in open-pit mines. Appl Ecol Environ Res 17(5): 10313-10333

Huang ZA, Zhang LH, Yang ZJ, Zhang J, Gao YK, Zhang YH (2019b) Preparation and properties of a rock dust suppressant for a copper mine. Atmos Pollut Res 10(6):2010-2017

Jin LZ, Yu M, Liu JY, Chu YN (2007) Experimental study on reducing the dust of explosion by the new water stemming. J China Coal Soc 32(3):31-35 
Kollipara VK, Chugh YP, Mondal K (2014) Physical, mineralogical and wetting characteristics of dusts from Interior Basin coal mines. Int J Coal Geol 127:75-87

Konorev MM, Nesterenko GF (2012) Present-day and promising ventilation and dust-and-gas suppression systems at open pit mines. J Min Sci 48(2):322-328

Li QZ, Lin BQ, Zhao S, Dai HM (2013) Surface physical properties and its effects on the wetting behaviors of respirable coal mine dust. Powder Technol 233:137-145

Liu JG, Jin LZ, Wang JY, Ou SN, Wang TY (2019a) Co-influencing mechanisms of physicochemical properties of blasting dust in iron mines on its wettability. Int $\mathrm{J}$ Miner Metall Mater 26:1080-1091

Liu JG, Jin LZ, Wang JY, Ou SN, Guo JZ, Wang TY (2019b) Micromorphology and physicochemical properties of hydrophobic blasting dust in iron mines. Int $\mathrm{J}$ Miner Metall Mater 26(6):665-672

Nie BS, Liu XF, Yang LL, Meng JQ, Li XC (2015) Pore structure characterization of different rank coals using gas adsorption and scanning electron microscopy. Fuel 158:908-917

Oberdörster G, Oberdörster E, Oberdörster J (2005) Nanotoxicology: an emerging discipline evolving from studies of ultrafine particles. Environ Health Perspect 113(7):823-839

Pérez J, Maldonado S, González-Ramírez R (2018) Decision support for fleet allocation and contract renegotiation in contracted openpit mine blasting operations. Int J Prod Econ 204:59-69

Petavratzi E, Kingman S, Lowndes I (2005) Particulates from mining operations: a review of sources, effects and regulations. Miner Eng 18(12):1183-1199

Singh PK, Roy MP, Paswan RK, Dubey RK, Drebenstedt C (2015) Blast vibration effects in an underground mine caused by openpit mining. Int J Rock Mech Min Sci 80:79-88

Susana L, Campaci F, Santomaso AC (2012) Wettability of mineral and metallic powders: applicability and limitations of sessile drop method and Washburn's technique. Powder Technol 226:68-77

Taylor MP, Mould SA, Kristensen LJ, Rouillon M (2014) Environmental arsenic, cadmium and lead dust emissions from metal mine operations: implications for environmental management, monitoring and human health. Environ Res 135:296-303

Tian Y, Jiang L (2013) Intrinsically robust hydrophobicity. Nat Mater 12(4):291-292

Wang HT, Zhang L, Wang DM, He XX (2017) Experimental investigation on the wettability of respirable coal dust based on infrared spectroscopy and contact angle analysis. Adv Powder Technol 28(12):3130-3139

Wang JY, Jin LZ, Guo JZ, Liu JG, Wang TY, Gong Q (2019a) Key influencing factors on wettability of blasting dust in Meishan Iron Mine. J Cent South Univ (Sci Technol) 50:2527-2535

Wang P, Tan X, Zhang L, Li Y, Liu R (2019b) Influence of particle diameter on the wettability of coal dust and the dust suppression efficiency via spraying. Process Saf Environ Prot 132:189-199

Xu CH, Wang DM, Wang HT, Xin HH, Ma LY, Zhu XL, Zhang Y, Wang QG (2017) Effects of chemical properties of coal dust on its wettability. Powder Technol 318:33-39

Xu G, Chen YP, Eksteen J, Xu JL (2018) Surfactant-aided coal dust suppression: a review of evaluation methods and influencing factors. Sci Total Environ 639:1060-1076

Yang J, Wu XK, Gao JG, Li GP (2010) Surface characteristics and wetting mechanism of respirable coal dust. Min Sci Technol (China) 20(3):365-371

Yu HM, Cheng WM, Xie Y, Peng HT (2018) Micro-scale pollution mechanism of dust diffusion in a blasting driving face based on CFD-DEM coupled model. Environ Sci Pollut Res 25(22):21768-21788

Zhou G, Xu CC, Cheng WM, Zhang Q, Nie W (2015) Effects of oxygen element and oxygen-containing functional groups on surface wettability of coal dust with various metamorphic degrees based on XPS experiment. J Anal Methods Chem 2015:1-8

\section{Publisher's note}

Springer Nature remains neutral with regard to jurisdictional claims in published maps and institutional affiliations. 